V. TOURNIER, C.M. TOPHAM, A. GILLES, B. DAVID, C. FOLGOAS, E. MOYA-LECLAIR,

E. KAMIONKA, M.-L. DESROUSSEAUX, H. TEXIER, S. GAVALDA, M. COT, E. GUÉMARD,

M. DALIBEY, J. NOMME, G. CIOCI, S. BARBE, M. CHATEAU, I. ANDRÉ*, S. DUQUESNE*,

A. MARTY* (UNIVERSITÉ DE TOULOUSE AND CARBIOS, SAINT-BEAUZIRE, FRANCE)

An Engineered PET Depolymerase to Break Down and Recycle Plastic Bottles

Nature 2020, 580, 216-219.

\title{
Enzymatic Depolymerization of Poly(ethylene terephthalate)
}<smiles>CCCCOC(=O)c1ccc(C(=O)OC)cc1</smiles>

polyethylene terephthalate (PET)

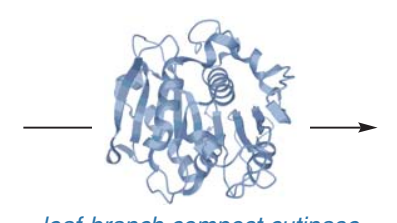

leaf-branch compost cutinase (LCC) variant 2n $\mathrm{H}_{2} \mathrm{O}$

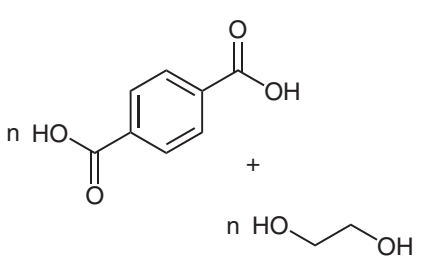

LCC quadruple variant

- improved activity and thermal stability

- melting $\mathrm{T}=94^{\circ} \mathrm{C}$

- $86 \%$ depolymerization $\left(72{ }^{\circ} \mathrm{C}\right)$

- $>90 \%$ in $10 \mathrm{~h}$ on pilot-scale

- melting $\mathrm{T}=84.7^{\circ} \mathrm{C}$

- $~ 55 \%$ depolymerization $\left(72{ }^{\circ} \mathrm{C}\right)$

molecular docking and enzyme contact surface analysis

X-ray structure-based identification of interatomic space suitable for a disulfide bridge

Analysis of all variants of step 1 in terms of activity and thermal stability identification of 11 relevant amino acids and testing of all 209 possible single mutations
Significance: The groups of Marty, Duquesne, and André collaboratively report the discovery of an engineered enzyme for the efficient depolymerization of poly(ethylene terephthalate) (PET). The authors describe the multistep process for the discovery of beneficial mutations to a wild-type leafbranch compost cutinase (LCC), an enzyme that by itself showed promising but insufficient activity toward PET degradation. It was shown that the thermal stability of the LCC is a particularly limiting factor. First, computer-based methods identified relevant amino-acid residues in the active site of the enzyme. All possible single-mutations were then synthesized and tested. In a second step, two amino acids were replaced by cysteine to form a stable disulfide bridge, significantly increasing the thermostability of the enzyme. Finally, the previously identified single mutations were implemented to restore catalytic activity and give the optimized biocatalyst.
Comment: PET is the most widely used polyester plastic worldwide; its primary uses include packaging and textiles. Because the collection and recycling rates of PET are relatively high compared with other plastics (K. Ragaert, L. Delva, K. Van Geem Waste Manag. 2017, 69, 24), efficient repurposing of waste material can be envisioned. Whereas thermomechanical recycling processes usually result in decreased product quality, degradation of the plastic into its monomers and de novo synthesis might be a viable alternative to close the loop of a circular economy. The process developed by the authors has proven efficient on a pilot-scale to produce high-purity terephthalic acid that was used for polymerization, yielding PET in bottle-grade quality. Altogether, these results indicate that (bio)chemical degradation of plastics might be industrially and economically feasible, and that the limiting factor for effective recycling processes will increasingly lie in political solutions and, ultimately, human behavior.

\section{Category}

Organo- and Biocatalysis

Key words

polyethylene terephthalate

polyester

depolymerization

enzyme engineering

recycling

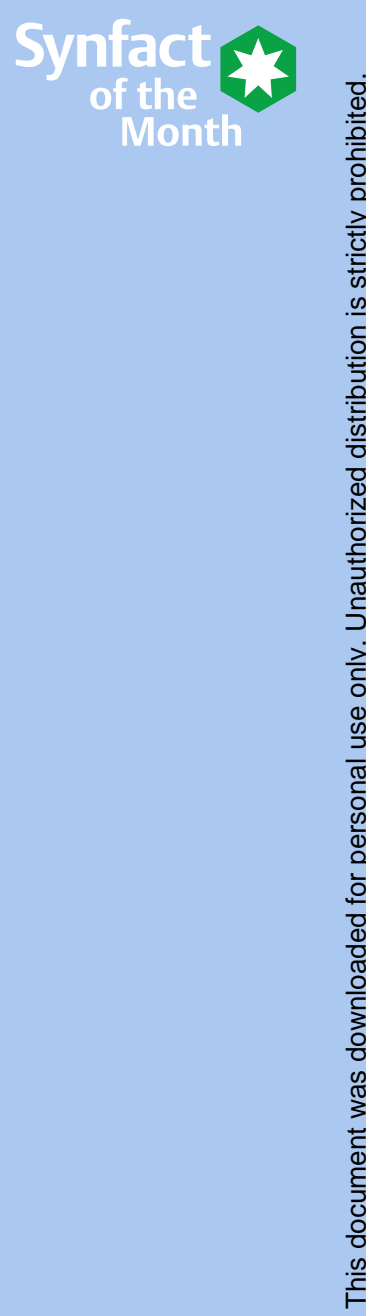

